\title{
Effect of Acid Fruit Juices Combined with Electric or Sonic Toothbrushing on Root Dentin Permeability - An In Vitro Study
}

\author{
Roberta Grasselli BATITUCCI \\ Daniela Leal ZANDIM \\ Fernanda Regina Godoy ROCHA \\ Michele Carolina PINHEIRO \\ Lucas Amaral FONTANARI \\ José Eduardo Cezar SAMPAIO
}

Department of Oral Diagnosis and Surgery, Araraquara Dental School, UNESP - Univ Estadual Paulista, Araraquara, SP, Brazil

\begin{abstract}
The purpose of this in vitro study was to quantify the alterations on human root dentin permeability after exposure to different acid fruit juices and to evaluate the effect of toothbrushing with electric or sonic toothbrush after acid exposure. The root dentin of 50 extracted third molars was exposed with a high speed bur. Crowns were sectioned above the cementoenamel junction and root fragments were used to prepare dentin specimens. Specimens were randomly assigned to 5 groups according to the fruit juice (kiwifruit, starfruit, green apple, pineapple and acerolla). Each specimen was connected to a hydraulic pressure apparatus to measure root dentin permeability using fluid filtration method after the following sequential steps: I) conditioning with $37 \%$ phosphoric acid for $30 \mathrm{~s}$, II) root scaling, III) exposure to acid fruit juices for $5 \mathrm{~min}$ and IV) electric or sonic toothbrushing without dentifrice for 3 min. Data were analyzed statistically by the Wilcoxon and Mann-Whitney tests at 5\% significance level. All fruit juices promoted a significant increase of dentin permeability while toothbrushing decreased it significantly $(p<0.05)$. It may be concluded that all acid fruit juices increased root dentin permeability, while toothbrushing without dentifrice after acid exposure decreased the permeability. The toothbrush mechanism (electric or sonic) had no influence on the decrease of root dentin permeability.
\end{abstract}

Key Words: acidic beverages, dentin, toothbrushing.

\section{INTRODUCTION}

Dentin hypersensitivity (DH) is a common clinical condition caused by the exposure of dentinal tubules in the oral environment $(1,2)$. According to Brännström's hydrodynamic theory, the transmission of stimuli through dentin involves the movement of fluids within the dentinal tubules (3). Therefore, dentin permeability is related to the transmission of pain in $\mathrm{DH}$.

The effect of erosive factors should be evaluated in DH treatment $(1,2,4)$. The frequency of acid foods and drinks intake has been associated to DH persistence $(1,2,4,5)$. Dietary acid substances are able to increase dentin permeability by opening dentinal tubules and, consequently, to induce DH (6).

Another etiological factor related to $\mathrm{DH}$ is the abrasion induced by brushing procedures on root surface. Brushing procedure can change dentin morphology and permeability $(1,2,4,7)$. In vitro investigations using scanning electron microscopy (SEM) have shown that smear layer is not acid resistant (5). However, these studies evaluated only surface morphology and changes on dentin permeability could not be measured (8). Zandim et al. (9) evaluated the effect of dietary acids (vinegar, orange juice, lemon juice, cola drink and white wine) and toothbrushing with electric toothbrush with or without toothpaste on root dentin permeability. It was verified that dietary acids increased dentin permeability, while brushing immediately after acid challenge decreased permeability levels. Similar results were observed by Pinto et al. (10). Sonic toothbrushing also promoted reduction of permeability after dentin exposure 
to dietary acids. These previous studies demonstrated that acids from diet are able to remove smear layer and increase dentin permeability. In addition, toothbrushing of dentin surface after dietary acid exposure reduces permeability level probably by partial occlusion of tubules with dentin debris. Difference between sonic and electric brushing procedures after acid exposure in dentinal tubule occlusion has not been previously evaluated. Therefore, the purpose of this in vitro study was to evaluate the combination of acid fruit juices and toothbrushing with electric (rotation-oscillation) and sonic toothbrushes on root dentin permeability.

\section{MATERIAL AND METHODS}

Fifty freshly extracted human third molars from young patients with mean age of 23 years were collected at the Araraquara Dental School, UNESP, after Ethics Committee's approval (Protocol \#52/04). The teeth were free of caries and restorations and had flat root surfaces. The teeth were stored for up to 2 weeks in capped tubes containing deionized water at room temperature.

Although an in vitro model cannot replicate in vivo conditions, it provides preliminary information to support clinical interventions. According to Özok et al. (11), dentin hydraulic conductivity increases with time after extraction and an equilibrium stage in dentin hydraulic conductance could be established 9 days after extraction. This interval was respected in the present study.

\section{Specimen Preparation}

Two parallel horizontal grooves were made on the flattest surface of each root under irrigation using high-speed cylindrical diamond burs (KG Sorensen, Barueri, SP, Brazil). Burs were introduced up to the middle of their active part to obtain standardized dentin depths of $1 \mathrm{~mm}$. The first groove was made at the cementoenamel junction and the second $4 \mathrm{~mm}$ bellow the first one. The cementum between the two grooves was removed with the same bur to expose the underlying dentin. The crowns were sectioned with diamond discs (KG Sorensen) above the first groove and only the root fragment was used. The pulp tissue was carefully removed with a Hedströen file, and the root was fixed with cyanoacrylate glue to a perforated plexiglass plate, which allowed fluid perfusion. Next, root surface was coated with nail polish, except for the exposed dentin surface in the cervical area.

\section{Dentin Permeability Evaluation}

Dentin permeability was evaluated using the fluid filtration method $(8,13)$. This method is based on quantifying the volume of fluid pushed through a dentin barrier under a hydrostatic pressure by time and pressure unit. In the present study, the visual observation of an air bubble movement that was manually introduced in the system by a syringe indicates the volume of fluid that passes the dentin barrier $(9,10)$. For dentin permeability evaluation, the root was connected to a fluid-filled system working at a pressure of $10 \mathrm{psi}$. A microcapillary tube with $25 \mu \mathrm{L}$ diameter was positioned between the pressure reservoir and the root. The microcapillary tube length was $65 \mathrm{~mm}$. The length and diameter of the microcapillary tube permitted calculation of dentin permeability $(9,10,12)$ (Fig. 1).

\section{Characteristics of the Acid Fruit Juices}

The fruits were acquired in a regional market. The juices were freshly obtained from squeezed fruit just before application. The $\mathrm{pH}$ of each fruit juice was measured with a single electrode $\mathrm{pH}$ meter (UB10; Denver Instrument, Arvada, CO, USA) at room temperature before each test.

\section{Experimental Design}

After preparation, specimens were randomly assigned to 5 groups $(\mathrm{n}=10)$, according to the fruit juice (kiwifruit, starfruit, green apple, pineapple, acerolla). The number of specimens per group was determined according to previous studies $(9,10)$. Each specimen was connected to the hydraulic pressure apparatus to measure the root dentin permeability after each of the following sequential steps: I: Treatment of dentin surface with $37 \%$ phosphoric acid for $30 \mathrm{~s}$ to obtain the maximum permeability (100\%); II: Root scaling with

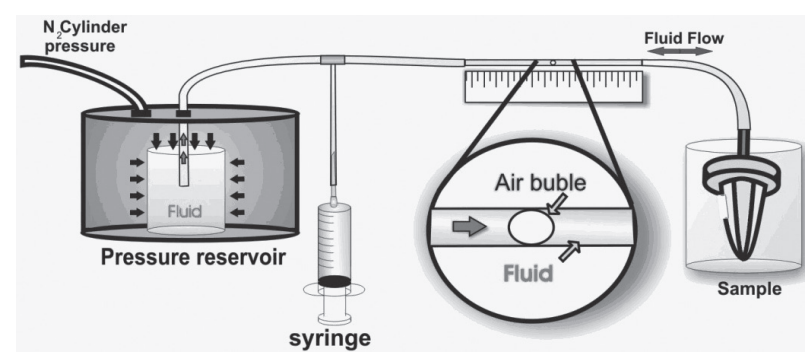

Figure 1. Pressure apparatus. 
Gracey 5-6 curettes (Millenium; Golgran Ind. e Com. de Instrumentos Odontológicos Ltda., São Paulo, SP, Brazil) using 50 strokes to create new smear layer; III: Immersion of the specimens in a plastic cup containing $5 \mathrm{~mL}$ of fruit juice for $5 \mathrm{~min}$; IV: Toothbrushing. Half of the specimens in each group $(n=5)$ were brushed with a sonic toothbrush and the other half $(n=5)$ with an electric toothbrush. The brushing procedures were manually performed with distilled water for $3 \mathrm{~min}$. No dentifrices were used.

After each step, the exposed dentin was rinsed with $10 \mathrm{~mL}$ of deionized water and the specimen was connected to the pressure apparatus to record dentin permeability. For each step, four measurements of dentin permeability were recorded and the median was calculated. The dentin permeability measured after step I was considered as $100 \%$ permeability and the subsequent steps were expressed as a percentage of this maximum value, which allowed comparisons between teeth (15) and the use of each specimen as its own control.

\section{Statistical Analysis}

Differences in dentin permeability values were evaluated by nonparametric analysis of variance, considering a $95 \%$ confidence interval. Wilcoxon test was performed to evaluate significant differences in step III in each group and Mann-Whitney test was used to evaluate differences among the 5 groups (acid fruit juices) after topical application. Mann-Whitney test was also used to evaluate differences between brushing procedures (sonic $\mathrm{x}$ electric toothbrush) within the same group. Pearson's correlation was used to evaluate the correlation between the $\mathrm{pH}$ of acid fruit juice and root dentin permeability after step III.

\section{RESULTS}

Table 1 shows the $\mathrm{pH}$ value of each fruit juice and the dentin permeability values after steps II, III and IV. Dentin exposed to phosphoric acid was used as the control group and assigned a $100 \%$ permeability value. The formation of a new smear layer using Gracey curettes reduced dentin permeability from $100 \%$ (step I) to a mean value of $35 \%$ (step II). After topical application (step III), all fruit juices increased significantly dentin permeability $(p<0.05)$. The highest increase of dentin permeability was observed in the acerolla group.

On the other hand, a reduction of dentin permeability was observed after brushing procedures (step IV) for all groups (Table 2). No significant difference was observed between the two tested types of toothbrushes, except for the kiwifruit group. In this group, the sonic toothbrushing promoted greater decrease of permeability than electric toothbrushing.

According to Pearson's analysis, there was no correlation between the $\mathrm{pH}$ value of the fruit juices and the dentin permeability observed after step III (Table 2).

\section{DISCUSSION}

The hydraulic conductance varies greatly with the level of dentinal tubule occlusion, surface area and dentin thickness. These parameters vary according to

Table 1. pH value and root dentin permeability of fruit juices after step II (smear layer creation), step III (fruit juice exposure) and step IV (toothbrushing).

\begin{tabular}{|c|c|c|c|c|c|}
\hline \multirow{2}{*}{ Fruit juices } & \multirow{2}{*}{$\mathrm{pH}$} & \multirow{2}{*}{ Step II } & \multirow{2}{*}{ Step III } & \multicolumn{2}{|c|}{ Step IV } \\
\hline & & & & Sonic toothbrush & Electric toothbrush \\
\hline Kiwi fruit & $3.19 \pm 0.06$ & $40.1 \pm 12.7 \underline{a}$ & $138.3 \pm 81.4^{\mathrm{bA}}$ & $47.9 \pm 22.6 \underline{\underline{\mathrm{aA}}}$ & $13.9 \pm 12.2^{\underline{b}}$ \\
\hline Star fruit & $3.75 \pm 0.19$ & $38.9 \pm 10.6^{\mathrm{a}}$ & $101.3 \pm 58.5 \underline{\mathrm{bA}}$ & $38.0 \pm 56.8 \underline{\mathrm{aA}}$ & $13.9 \pm 12.2^{\mathrm{a}}$ \\
\hline Green apple & $3.86 \pm 0.15$ & $34.3 \pm 12.1^{\mathrm{a}}$ & $105.9 \pm 38.4 \mathrm{bA}$ & $16.3 \pm 11.4^{\mathrm{a}}$ & $20.5 \pm 16.5$ \\
\hline Pineapple & $3.41 \pm 0.07$ & $29.3 \pm 20.2^{\mathrm{a}}$ & $98.8 \pm 46.6^{\mathrm{bA}}$ & $16.3 \pm 12.0^{\mathrm{a}}$ & $22.6 \pm 8.9 \mathrm{aA}$ \\
\hline Acerolla & $3.29 \pm 0.15$ & $36.1 \pm 15.3^{\mathrm{a}}$ & $176.8 \pm 63.7 \underline{\mathrm{bB}}$ & $32.5 \pm 37.1^{\mathrm{a}}$ & $30.8 \pm 20.1 \underline{\mathrm{aA}}$ \\
\hline
\end{tabular}

Steps II, III and IV: Permeability values are expressed as percentage of Step I (100\%); Steps II and III: Groups identified by different superscript lowercase letters within the same row are significantly different $(\mathrm{p}<0.05$; Wilcoxon test); Step IV: Groups identified by different superscript lowercase letters within the same row are significantly different ( $p<0.05$; Mann Whitney test); Steps II and III: Significant differences among the acid juices are represented by different superscript uppercase letters ( $<<0.05$; Mann-Whitney test); Step IV: Significant reduction in root dentin permeability compared with previous Step III value is identified by uppercase letter A ( $p<0.05$; Wilcoxon test). Values are expressed as mean \pm SD. 
the experimental conditions. Researchers should report the hydraulic conductance of dentin in their studies in order to have appropriate laboratory comparisons $(2,6)$. The tooth is unique in terms of dentinal tubule density (16). Therefore, this study used the tooth as its own control. After specimen etching, dentin permeability was measured and this value was considered as the maximum permeability (100\%). Permeability changes produced by the experimental steps were considered as a percentage of this maximum value. In this experimental design, the tooth is its own control. For this reason, different tooth types could be used. However, only third molars were used because these teeth are easy to obtain and are usually extracted without caries and/or restorations. In addition, specimens with similar initial permeability were used to avoid great variability among the groups. In this study, the permeability of the cervical root dentin was evaluated in order to use the area where these lesions are usually located $(9,10)$.

Periodontal treatment and periodontal disease play a role in the prevalence of DH (17). Periodontal attachment loss and periodontal treatment lead to root dentin exposure and probably increase root dentin permeability (8). The results of this study showed that after phosphoric acid etching (step I), i.e. in a dentin surface free of smear layer, the scaling procedure (step II) promotes the decrease of dentin permeability, corroborating other studies (8-10), probably due to the formation of smear layer.

The magnitude of change in the values of permeability before and after acid etching indicates the thickness or density of the smear layer. For this reason, teeth that have little smear layer have higher initial permeability, but these values will not change much after etching, because there is little debris covering the tubules (18). Therefore, all samples were scaled by a single operator in a standardized manner (50 incisal-

Table 2. Pearson's correlation coefficient (r) between the $\mathrm{pH}$ of fruit juice and root dentin permeability after step III (fruit juice exposure; $\mathrm{p}<0.05$ ).

\begin{tabular}{lcc}
\hline Fruit juices & Pearson's $r$ & $\mathrm{p}$-value \\
\hline Kiwifruit & 0.331 & 0.350 \\
Starfruit & -0.385 & 0.272 \\
Green apple & 0.032 & 0.931 \\
Pineapple & 0.265 & 0.459 \\
Acerolla & -0.426 & 0.220 \\
\hline
\end{tabular}

apical strokes) $(9,10)$. The smear layer was formed similarly, minimizing the variability in permeability among the samples.

In vitro studies indicate that acid substances from patient's diet can remove the smear layer exposing dentin tubules $(5,6,9,10)$ and increase dentin permeability by opening dentinal tubules $(6,9,10)$. Acidic drinks increased dentin permeability by removing and dissolving the smear layer as well as by demineralization of intertubular matrix, which promote expansion of dentinal tubules $(6,7)$.

The protocol used in the present study was in accordance with previous studies $(9,10)$. After removal of cementum with a high-speed dental bur, dentin surface was subjected to etching procedure (step I) to obtain the maximum permeability value. Next, scaling (step II) was performed, which led to a significant reduction in dentin permeability $(p<0.05)$ (Table 1$)$. Therefore, the action of the curette on the acid-etched dentin surface led to smear layer formation. The subsequent exposure to acid fruit juices (step III) promoted a significant increase $(p<0.05)$ on dentin permeability in all groups (Table 1). This result confirms that the smear layer formed by root scaling does not resist to dietary acids $(9,10)$.

The $\mathrm{pH}$ value of the fruit juices used in this study did not show correlation with dentin permeability (Table 2). All tested fruit juices were in a similar $\mathrm{pH}$ range (Table 1). However, other factors such as type of acid, buffering capacity, total acidity and $\mathrm{C}$ vitamin content might have influenced the results (19). All acid juices increased dentin permeability after topical application. However, acerolla juice produced significantly higher values of permeability compared with the other fruit juices (kiwifruit, starfruit, green apple, and pineapple) $(\mathrm{p}<0.05)$ (Table 1). This result may be associated with the higher $\mathrm{C}$ vitamin content in acerolla juice.

This study also aimed to evaluate the effect of sonic and electric toothbrushing subsequent to acid exposure on dentin permeability (step IV). Some authors have stated that toothbrushing followed by the intake of acid substances produces a higher rate of abrasion, leading to hard tissue loss $(1,2,4)$. Nevertheless, brushing of the dentin surface immediately after acid challenge led to dentin permeability reduction, probably by the formation of smear layer. The different toothbrushes used (sonic and electric) promoted similar reduction in dentin permeability, except for the kiwifruit group, in which sonic toothbrushing promoted significantly $(\mathrm{p}<0.05)$ higher reduction in dentin permeability than electric 
toothbrushing. According to this study, the results of Zandim et al. (9) showed that toothbrushing with electric toothbrush after acid exposure reduced the permeability levels. Pinto et al. (10) observed similar results using sonic toothbrush. The higher decrease in permeability observed in kiwifruit by the sonic toothbrush is probably because this toothbrush was first used in this group.

The results of this study are an alert to patients with DH to avoid excessive intake of acid fruits. For an effective DH treatment, etiological factors must be removed, which includes educating patients for a non-traumatic toothbrushing and dietary counseling, especially with regard the consumption of fruit juices combined with toothbrushing.

Evaluating the changes in root dentin permeability in the above-mentioned experimental conditions, it may be concluded that: 1 . Scaling of root dentin after acid etching reduced dentin permeability; 2 . Exposure to the tested acid fruit juices led to a significant increase in dentin permeability; 3 . The $\mathrm{pH}$ of the tested acid fruit juices did not correlate with permeability values; 4 . The toothbrush mechanism (rotation-oscillation or sonic) did not influence root dentin permeability after exposure to acid fruit juices, except for the kiwifruit group, in which sonic brushing promoted a significantly greater permeability decrease.

\section{RESUMO}

O objetivo deste trabalho in vitro foi quantificar as alterações na permebilidade da dentina radicular humana após exposição a diferentes sucos de frutas ácidas e avaliar o efeito da escovação, com escova elétrica ou sônica, após a exposição ácida. A dentina radicular de 50 terceiros molares foi exposta com a utilização de fresas em alta rotação. As coroas foram seccionadas acima da junção cemento-esmalte e apenas os fragmentos radiculares foram utilizados no preparo dos espécimes. Os espécimes foram aleatoriamente divididos em 5 grupos de acordo com o suco de fruta aplicado (kiwi, carambola, maça verde, abacaxi e acerola). Cada espécime foi conectado a um aparelho de pressão para medir a permeabilidade dentinária por meio do método de filtração de líquidos após as seguintes etapas sequências: I) condicionamento com ácido fosfórico $37 \%$ durante 30 s, II) raspagem da raiz, III) exposição aos sucos de frutas por $5 \mathrm{~min}$, IV) escovação com escova elétrica ou sônica durante $3 \mathrm{~min}$. Os dados foram analisados estatisticamente pelos testes Wilcoxon e Mann-Whitney com nível de significância de 5\%. Os resultados mostraram que todos os sucos de frutas testados promoveram aumento significativo da permeabilidade dentinária e os procedimentos de escovação causaram diminuição. Pode-se concluir que os sucos de frutas ácidas aumentaram a permeabilidade da dentina radicular, enquanto que a escovação sem dentifrício imediatamente após a exposição ácida promoveu redução da permeabilidade. Além disso, o mecanismo da escova (elétrica ou sônica) não teve influência na redução da permeabilidade dentinária.

\section{ACKNOWLEDGEMENTS}

The authors would like to thank CAPES for granting a scholarship to one of the authors.

\section{REFERENCES}

1. Orchardson R, Gillam DG. Managing dentin hypersensitivity. J Am Dent Assoc 2006;137:990-998.

2. Bartold PM. Dentinal hypersensitivity: a review. Aust Dent J 2006;51:212-218.

3. Brännström M, Aström A. The hydrodynamics of the dentine; its possible relationship to dentinal pain. Int Dent J 1972;22:219-227.

4. Addy M. Clinical aspects of dentine hypersensitivity. Proc Finn Dent Soc 1992;88:23-30.

5. Zandim DL, Correa FO, Rossa Junior C, Sampaio JE. In vitro evaluation of the effect of natural orange juices on dentin morphology. Braz Oral Res 2008;22:176-183.

6. Prati C, Montebugnoli L, Suppa P, Valdre G, Mongiorgi R. Permeability and morphology of dentin after erosion induced by acidic drinks. J Periodontol 2003;74:428-436

7. Mjor IA. Dentin permeability: the basis for understanding pulp reactions and adhesive technology. Braz Dent J 2009;20:3-16.

8. Fogel HM, Pashley DH. Effect of periodontal root planning on dentin permeability. J Clin Periodontol 1993;20:673-677.

9. Zandim DL, Leite FR, Sampaio JE. In vitro evaluation of the effect of dietary acids and toothbrushing on human root dentin permeability. Quintessence Int 2010;41:257-263.

10. Pinto SC, Batitucci RG, Pinheiro MC, Zandim DL, Spin-Neto R, Sampaio JE. Effect of an acid diet allied to sonic toothbrushing on root dentin permeability: an in vitro study. Braz Dent $\mathrm{J}$ 2010;21:390-395.

11. Ozok AR, Wu MK, Wesselink PR. The effects of post-extraction time on the hydraulic conductance of human dentine in vitro. Arch Oral Biol 2002;47:41-46.

12. Prati C. What is the clinical relevance of in vitro dentine permeability tests? J Dent 1994;22:83-88.

13. Pashley DH. Dentin permeability and dentin sensitivity. Proc Finn Dent Soc 1992;88:31-37.

14. Pereira JC, Segala AD, Gillam DG. Effect of desensitizing agents on the hydraulic conductance of human dentin subjected to different surface pre-treatments - an in vitro study. Dent Mater 2005;21:129-138.

15. Greenhill JD, Pashley DH. The effects of desensitizing agents on the hydraulic conductance of human dentin in vitro. J Dent Res 1981;60:686-698.

16. Taani SD, Awartani F. Clinical evaluation of cervical dentin sensitivity (CDS) in patients attending general dental clinics (GDC) and periodontal specialty clinics (PSC). J Clin Periodontol 2002;29:118-122.

17. Pashley DH, Kepler EE, Williams EC, Okabe A. The effects of acid etching on the in-vivo permeability of dentine in the dog. Arch Oral Biol 1983;28:555-559.

18. Hughes JA, West NX, Parker DM, van den Braak MH, Addy M. Effects of $\mathrm{pH}$ and concentration of citric, malic and lactic acids on enamel, in vitro. J Dent 2000;28:147-152.

Received August 25, 2011

Accepted November 5, 2012 